Original Research Paper

\title{
Enhancement Effect of BAP and Spent Mushroom Compost in Micro-Propagation of Sabah Snake Grass
}

\author{
${ }^{1}$ Wan Nurul Hidayah Wan Anuar, ${ }^{2}$ Suat-Hian Tan, ${ }^{2}$ Siti Hamidah Radiyah Shiekh Mahmud, ${ }^{2}$ Wan \\ Nurhafisya Binti Mior Norazmi and ${ }^{3}$ Engku Fatimah Syairah Engku Safruddin \\ ${ }^{1}$ Faculty of Applied Sciences, Universiti Teknologi MARA,Perak Branch, Tapah Campus,Tapah Road, Malaysia \\ ${ }^{2}$ Faculty of Industrial Sciences and Technology, Universiti Malaysia Pahang, Kuantan, Pahang, Malaysia \\ ${ }^{3}$ Faculty of Applied Sciences, Universiti Teknologi MARA, Perlis Branch, Arau Campus, Perlis, Malaysia
}

\author{
Article history \\ Received: 17-04-2019 \\ Revised: 22-08-2019 \\ Accepted: 23-10-2019 \\ Corresponding Author: \\ Suat-Hian Tan \\ Faculty of Industrial Sciences \\ and Technology, Universiti \\ Malaysia Pahang, Kuantan, \\ Pahang, Malaysia \\ Email: tshian@ump.edu.my
}

\begin{abstract}
Medicinal plants which is Clinacantus nutans (C. nutans) that known as Sabah Snake Grass or Belalai Gajah can treat several diseases including cancer. In order to provide and grow this plant in large number for health and pharmaceutical industry, one of the solutions is through the plant tissue culture technique. In this experiment, $C$. nutans was cultured under controlled conditions which to provide sterile plantlets. The surface sterilization using three methods which involved ethanol, Clorox and mercuric chloride. In the comparison of them, it was found that the use of $70 \%$ ethanol $(5 \mathrm{~min})$ followed by $30 \%$ clorox $(5 \mathrm{~min}$ ) then with $0.1 \%$ mercuric chloride for one hour was the most effective sterilization method which gave the highest survival rate $(100 \%)$ and zero contamination rate. The sterile explants were then cultured in media containing different concentrations of Benzylaminopurine (BAP) and Pleurotus ostreatus Spent Mushroom Compost (SMC). The SMC was tested and compared in powder and extracted form. The observations were made every week on responds of the culture using variables which are number of shoots, length of shoots and number of leaves. This article was aimed to evaluate the enhancement effect of BAP and SMC in micro-propagation of Sabah Snake Grass. The authors found that the best concentration for BAP is $1.0 \mu \mathrm{M}$. It produced $3.5 \pm 0.926$ number of shoots and $2 \mu \mathrm{M}$ BAP produced $7.286 \pm 1.496$ number of leaves in their findings. When BAP and SMC were tested in combination, they managed to produce high number of shoots and leaves. Their result revealed a number of shoots $(5.750 \pm 0.500)$ produced by $2 \%$ extract of SMC and some leaves $(11.890 \pm 1.965)$ by $8 \%$ extract of SMC when both were cultured together with $1.0 \mu \mathrm{M}$ BAP respectively. The authors thought that there was enhancement effect on the combination of BAP with extracts of SMC which gave about double regeneration rate as compared with the BAP alone and this method had high potential for future research in producing mass propagation of $C$. nutan and other related study by reducing the usage of plant growth regulator which may reduce the cost of micro-propagation of tissue culture plants.
\end{abstract}

Keywords: Medicinal Plant, In vitro Culture, Plant Hormone, Pleurotus Ostreatus

\section{Introduction}

In Malaysia, sabah snake grass, pegaga and kacip fatimah are example of medicinal herbs that commonly known and consumed by many people. These medicinal herbs had been grown commercially in Malaysia due to the fact treating certain diseases. According to research conducted by Tan and Mahmood (2013), medicinal herb extract can help for treatment of leprosy and healing wound. This medicinal plant also implies important part as therapeutic agent or an active agent. One of the medicinal plant which can give benefits through the proven research conducted before is Clinacanthus nutans (Yong et al., 2013). Clinacanthus come from family of Acanthacea, 
flowering herb and medicinal plants that widely distributed. It had known to treat nettle rash, dysentery and insect bites not only in Malaysia but also other Southeast Asia countries (Tiew et al., 2014). The leaves of C. nutans have long been used traditionally and now have led to discovery of analgesic and anti-inflammatory effect through modern research conducted by scientists. This important discovery had largely concern by the pharmaceutical companies thus increasing the demand of the herb. There are several plants from Acanthacea family successfully grown in vitro, conducted by other researches (Janarthanam and Sumathi, 2010; Suriyavathana and Kumar, 2010). The plant tissue culture technique had made the possibility of fulfilling the high demand by propagating the plant in larger number.

The plant tissue culture technique is a technique proposed by scientist to grow plant for rapid propagation. This technique is conducted within controlled environment as the plant is provided with adequate amount of nutrient in artificial media. The $C$. nutans which is usually grown in the soil is subjected to be grown in vitro as there is limited study related. The $C$. nutans plants propagation is limited to seeds where germination using seed in natural conditions is poor as compared to using shoots. The meristematics cells located at the shoot excised can functionally help in triggering the growth of new cells in young plantlet thus forming new buds after cultured directly on medium.

The protocol developed in the studies enable for long-term in vitro conservation and mass propagation of species (Bouhouce and Tsiksi, 2007). There are many factors that affect the plant regeneration. This study focuses on the plant growth regulator as one of the factors that help in promoting the growth of the plant.

Plant growth regulator is a significant option used to control and modify the growth of plant. Plant growth regulator can increases the production of secondary metabolites of medicinal plant (Tan et al., 2010). Plant growth regulators also referred as plant hormones or phytohormones, which synthesized naturally or in laboratory. There are several classes of plant hormones. Each of the classes of hormones can give variety of growth and morphogenetic responses and each is pleiotropic in its effect (Srivastava, 2001). Other than for the growth of plant, the plant hormones also have been used in manipulating the biosynthesis of secondary metabolite in plant (Tan et al., 2013).

The Pleurotus ostreatus Spent Mushroom Compost (SMC) is an agricultural waste that able to be converted into usable product for growth of plant. It is an effective material that can improve soil structure owing to its high organic matter content and the availability of essential plant nutrients (Jordan et al., 2008). Pleurotus ostreatus that came from the genus Pleurotus is a class of edible mushroom that has the capacity to convert nutritionally valueless substances into high protein food, acquire high saprophytic ability and can grow on a variety of cellulosic wastes (Akinyele et al., 2012). SMC is obtained in cultivation farm and can be grown in rubber tree sawdust and rice husk types of medium. It can provide carbon and mineral source which improve the plant growth through shoot regeneration. In this project, an efficient protocol was reported for plant regeneration from stem explant of $C$. nutans by studying the addition of SMC into media containing plant hormone which is Benzylaminopurine (BAP).

\section{Experimental Details}

The naturally planted $C$. nutans was obtained from the plant nursery in Arau, Perlis, Malaysia. The stem was sterilised prior to culture in the germination medium. The SMC was obtained from $\mathrm{C}$ and $\mathrm{C}$ Mushroom Cultivation Farm, Johor, Malaysia and further ground into powder form using grinder.

Three different treatment with different percentage of ethanol, Clorox and present of mercuric chloride as listed in Table 1 were used to optimized the surface sterilization of the nodal segments of $C$. nutans. The best treatment which is treatment 3 were used for the all others experiments. The nodal segments of $C$. nutans was underwent surface sterilization using $70 \%$ ethanol for 5 minutes, followed by $30 \%$ Clorox. The nodal segment lastly immersed in $0.1 \%$ mercuric chloride for one hour. Then, they were rinsed using sterile distilled water before inoculated onto the germination medium.

The full strength basal Murashige and Skoog (MS) medium were used as the germination medium. The medium was supplemented with $3 \%$ sucrose and gelled with $2.2 \%(\mathrm{w} / \mathrm{v})$ of gelrite. The germination medium was supplemented with plant hormone which was BAP at different concentrations which are $0.01,0.1,1.0$ and 2.0 $\mu \mathrm{M}$. No further increase for concentration of plant hormone to minimize the use of plant hormone. After inoculation, the cultures were incubated in $25^{\circ} \mathrm{C}$ under $16 \mathrm{~h}$ of photoperiods.

The SMC were ground and sieved into powder form with particular size of $150 \mu \mathrm{m}$. The SMC powder was then extracted using a tap water solution for $10 \mathrm{~g}$ per $50 \mathrm{~mL}$ of tap water. The SMC-tap water mixture was shake at 200 rpm for $2 \mathrm{~h}$ at $25 \pm 2^{\circ} \mathrm{C}$. The mixture was then centrifuged at $6000 \times \mathrm{g}$ at $4^{\circ} \mathrm{C}$ for $5 \mathrm{~min}$. The supernatant which contain the extract was collected and stored. Then, the powder and extract form of SMC was added into the MS media that contained 1.0 $\mu \mathrm{M}$ BAP respectively. The concentrations used for powder and extract were $2 \%, 4 \%$ and $8 \%$ per liter of media. This is the prior concentration to test for micropropagation of $C$. nutans.

The experiment was performed with a minimum of 3 replicates for each treatment and each was repeated two times. The data such as the number of shoots, the length of shoots and the number of leaves of $C$. nutans recorded were statically analysed by one-way analysis of variance (ANOVA) to detect the significance different between means and Tukey's test at 5\% probability level. 


\section{Result}

The culture of young explants in vitro were favoured as it highly potential in morphogenetic and low contamination rate (Tan, 2017). In order to obtain sterile explant, three techniques were tested to find the most effective method with the lowest contamination rate. Table 1 shows the survival rate and contamination rate based on the three different technique of sterilization for C. nutans explant. From Table 1, Treatment 3 has shown to has the highest survival rate $(1.000 \pm 0.000)$ compared to the Treatment $1(0.220 \pm 0.190)$ and Treatment 2 $(0.567 \pm 0.196)$. All the triplicates for the Treatment 3 survived with no contamination.

The stem explants enlarged and emerged new shoots at the cut surfaces after 10 to 14 days of inoculation in all germination media supplemented with BAP. The morphology of the explant is as shown in Fig. 1. The result for induction of shoot for $C$. nutans were recorded using three parameters which were number of shoots, length of shoots and number of leaves. The development of shoots and leaves was observed after the single shoots were cultured in media containing different concentrations of BAP. Figure 2a shows the variability in measurement number of leaves for proliferation of $C$. nutans. The highest mean number of leaves is $2.0 \mu \mathrm{M}$ of BAP with an average of $7.2857 \pm 1.4960$. The $0.1 \mu \mathrm{M}$ of BAP showed intermediate reading of the mean number of leaves compared to $0.01 \mu \mathrm{M}$ and $1.0 \mu \mathrm{M}$ BAP with the value of $5.375 \pm 1.496$, which is significant different to $0.01 \mu \mathrm{M}$ and $2.0 \mu \mathrm{M}$ of BAP. The lowest mean number of leaves was recorded from $0.01 \mu \mathrm{M}$ of BAP which is $2.429 \pm 0.5345$. Based on Fig. 2b, the maximum number of shoots per explant were initiated at $1.0 \mu \mathrm{M}$ of BAP with $3.5 \pm 0.926$ followed by $2.0 \mu \mathrm{M}$ of BAP $(2.714 \pm 0.756)$ and $0.1 \mu \mathrm{M}$ $(2.714 \pm 1.113)$ respectively. Less number of shoots produced when explant inoculated in germination media supplemented with $0.01 \mu \mathrm{M}$ BAP $(1.858 \pm 0.378)$. This show $1.0 \mu \mathrm{M}$ of $\mathrm{BAP}$ is enough for stimulation proliferation of shoot in this medicinal plant which is in agreement with Gulab et al. (2011). Figure 2c indicates the linear increase in the graph length of shoots from 0.01 $\mu \mathrm{M}$ to $2.0 \mu \mathrm{M}$ of BAP. The highest length of shoots is 2.0 $\mu \mathrm{M}$ BAP $(1.316 \pm 0.6768)$ followed by $1.0 \mu \mathrm{M}$ BAP $(0.9625 \pm 0.4005)$ and $0.1 \mu \mathrm{M}$ BAP $(0.6 \pm 0.3123)$. The
2.0 $\mu \mathrm{M}$ BAP highly significance different compared to others concentration which indicates the greater demand of hormone for higher growth of $C$. nutans.

Upon controlling the use of plant growth regulator, 1.0 $\mu \mathrm{M}$ BAP was chosen and combined either with media of extract SMC or powdered SMC media. The SMC supplemented in form of powder or extract with concentrations of $2 \%, 4 \%$ and $8 \%$ per liter of media, respectively. The same parameters were used and all the result for various concentration were recorded as shown in Fig. 3. The result pattern showed that the addition of extract or powdered SMC in the media supplemented with BAP showed a statistically increase trend in propagation. The observation done for five weeks showed that the extracts form of SMC produced higher number of leaves, number of shoots and length of shoots compared to the powdered and control (absent of SMC in media).

The leaves were induced from shoots of explant after 3 weeks of culture on germination medium supplemented with extract or powdered SMC. Between the concentrations of extract and powdered SMC, extract of SMC was the most effective in promoting leaves proliferation compared to powdered form as shown in Fig. 3a. C. nutans explant inoculated in $8 \%$ extract had the maximum generation of leaves with value of $11.890 \pm 1.965$. This is followed by $4 \%$ extract $(10.334 \pm 1.872)$ and $2 \%$ of extract $(6.44 \pm 0.421)$. Whereas for the powdered SMC, the leaves proliferated for $2 \%$ and $4 \%$ are low but increase steeply for $8 \%$.

The best response for highest shoot formation was produced with germination medium containing $2 \%$ of extract SMC which is $5.750 \pm 0.500$ as recorded in Fig. 3b. The medium containing $8 \%$ of extract SMC also promoted high shoot regenerate $(2.671 \pm 0.320)$ followed by $4 \%$ extract of SMC $(2.332 \pm 0.311)$. The germination medium supplemented with $2 \%, 4 \%$ and $8 \%$ of powdered SMC show no significant different in the formation of shoots. Figure 4 shows the different in morphology of $C$. nutans cultured in media containing powdered SMC and extract SMC.

The stem explant cultured in medium supplemented with extract or powdered SMC produced well-developed shoots with different length. The length of multiple shoots induction varied with the concentration of extract and powdered SMC (Fig. 3c).

Table 1: Survival rate and contamination rate

\begin{tabular}{llll}
\hline Treatment & Technique & Survival rate & Contamination rate \\
\hline T1 & $30 \%$ ethanol $(5 \mathrm{~min})$, & $0.220 \pm 0.190$ & $0.780 \pm 0.191$ \\
& $70 \%$ Clorox $(5 \mathrm{~min})$ & \\
T2 & $70 \%$ ethanol $(5 \mathrm{~min})$, & $0.567 \pm 0.196$ & $0.443 \pm 0.196$ \\
& $30 \%$ Clorox $(5 \mathrm{~min})$ & & $0.000 \pm 0.000 *$ \\
T3 & $70 \%$ ethanol $(5 \mathrm{~min})$, & $1.000 \pm 0.000^{*}$ & \\
& $30 \%$ Clorox $(5 \mathrm{~min})$, & & \\
& $0.1 \%$ mercuric chloride $(1 \mathrm{~h})$ & & \\
\hline
\end{tabular}

Note: The result was obtained from the mean \pm standard deviation. The mean difference is significant at the 0.05 level which denoted with* 


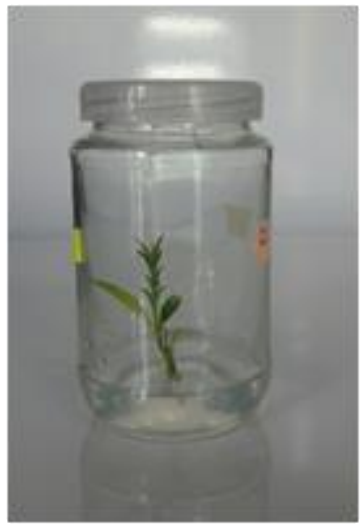

Fig. 1: C.nutans explant after 4 weeks of culture in media containing BAP
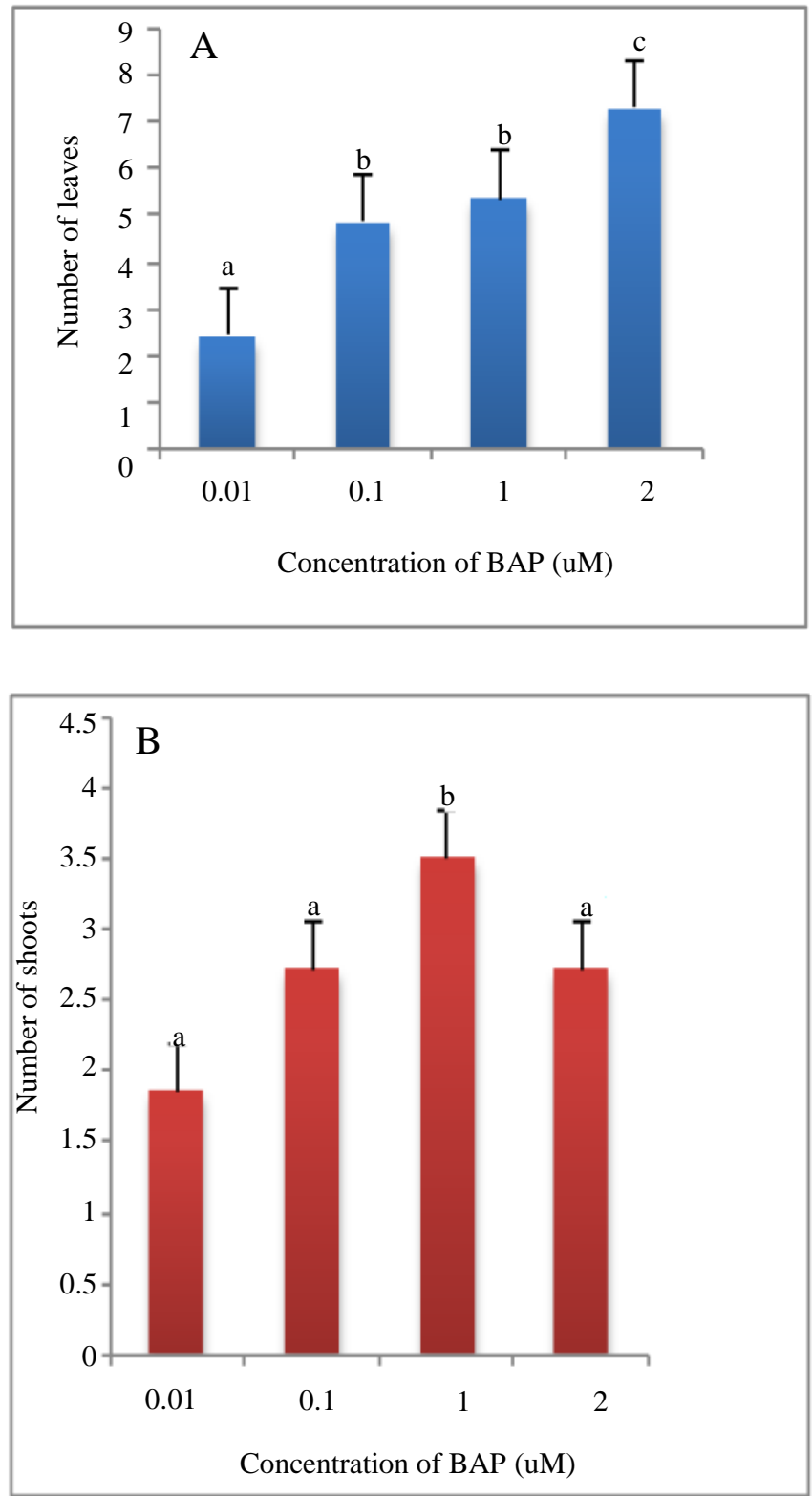


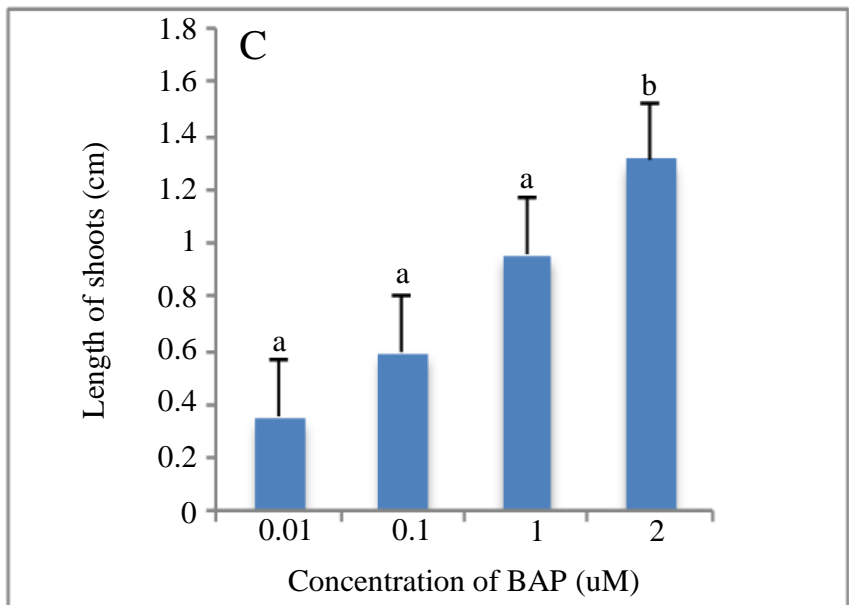

Fig. 2: (a) Number of Leaves (b) Number of Shoots (c) Length of Shoots of $C$. nutans with Different Concentrations of BAP after 4 weeks. The different letter on the bar indicates the standard deviation of mean $(n=3)$ which significantly difference at $\mathrm{p}<0.05$.

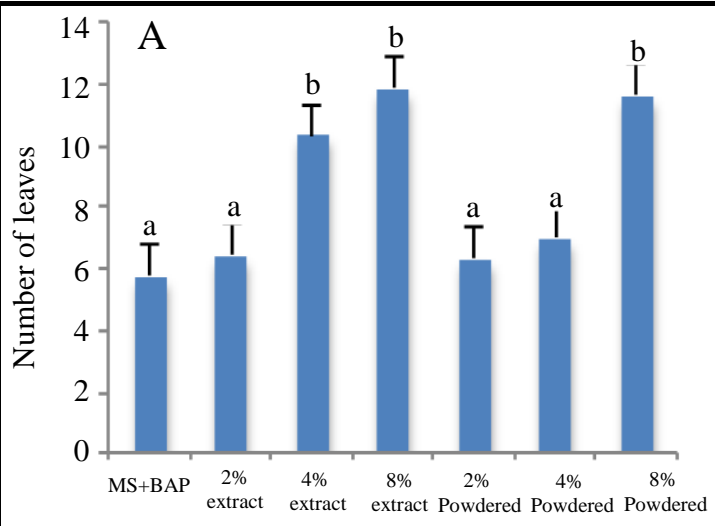

Concentration

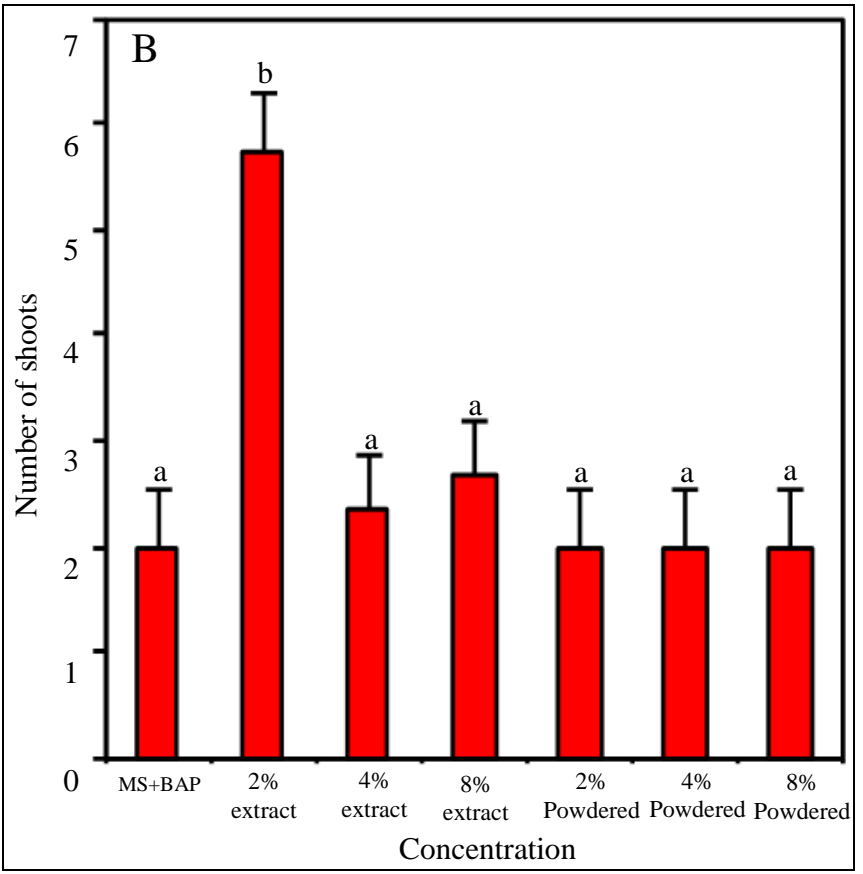




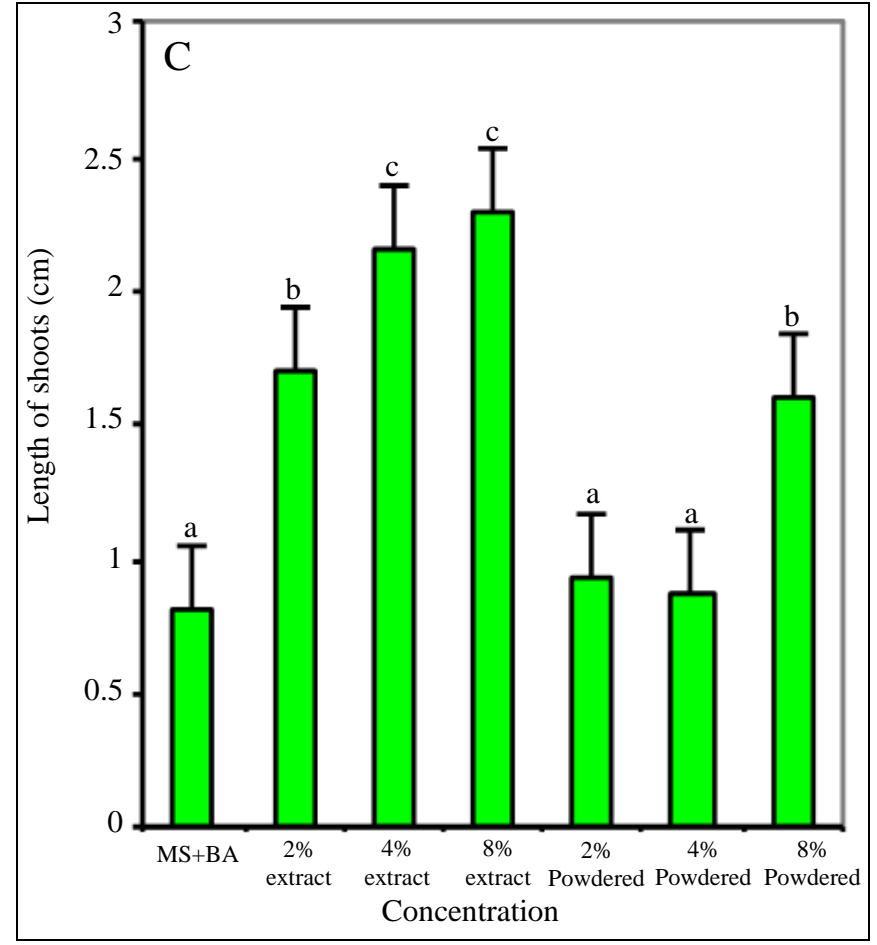

Fig. 3: (a) Number of Leaves (b) Number of Shoots (c) Length of Shoots of C. nutans with Different Concentrations of extract and powdered SMC after 5 weeks. The different letter on the bar indicates the standard deviation of mean $(n=3)$ which significantly difference at $\mathrm{p}<0.05$
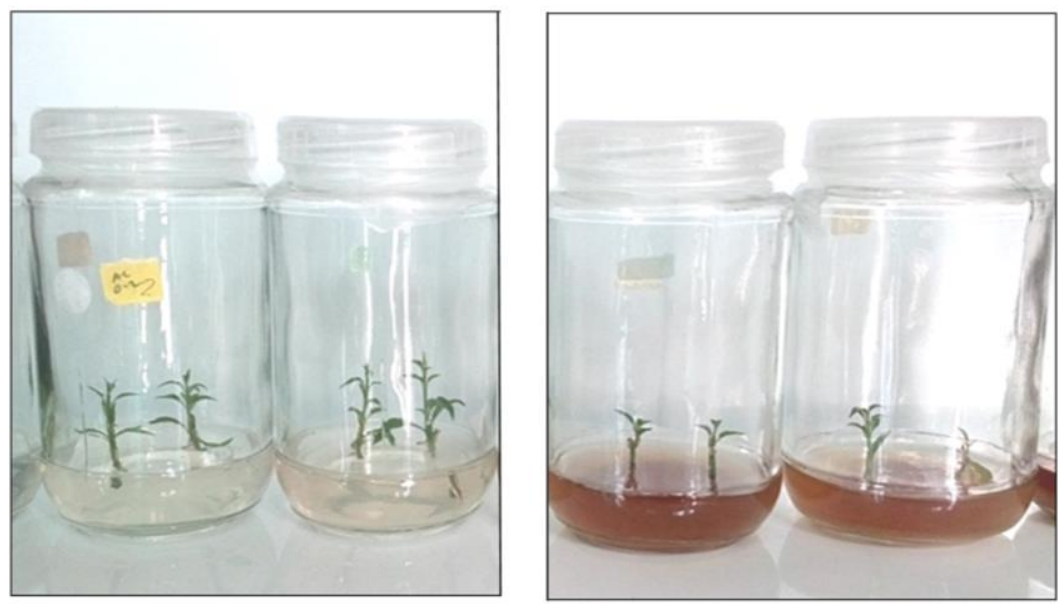

Fig. 4: Differences in length of shoots and number of leaves of $C$. nutans in media supplemented with extracts SMC (left) and powdered SMC (right)

There are significantly different in length of shoots from the explant that cultured on germination medium containing $8 \%$ extracts $(2.300 \pm 0.200)$ followed by $4 \%$ extracts $(2.156 \pm 0.188)$ and $2 \%$ extract $(1.7 \pm 0.211)$.

\section{Discussion}

Sterilization using $70 \%$ ethanol and $30 \%$ Clorox was proven to be effective (Singh et al., 2011) as various herbal plants have shown to have a satisfactory result with less microorganism colony count. For this research, $0.1 \%$ mercuric chloride was added in the treatment 3 to increase the sterilization of the explants. The additional of mercuric chloride has help to reduce up to $100 \%$ with no contamination risk. The use of $30 \%$ ethanol and $70 \%$ Clorox for treatment 1 that shows lowest rate of survival indicates that lower concentration of ethanol unable to fully eliminate and kill microoorganisms that present on the explant. 
The results, concentration of BAP with $0.01 \mu \mathrm{M}$ is enough for stimulation proliferation of shoot in $C$. nutans. However, the medium supplemented with 2.0 $\mu \mathrm{M}$ of BAP was proven to be the best for shoot and leaves induction. This is in agreement with other species of medicinal plants (Taški-Ajduković and Vasić, 2005; Soibam et al., 2013). The stimulatory effect of the cytokinin hormone such as BAP had increases the abilities of plant to produced more shoots and leaves. This also depends on the concentration of BAP as to enhance the multiple shoot induction from nodal cutting (Thomas and Shankar, 2009). The germination medium supplemented with powdered SMC show no significant different in the formation of shoots for all the concentrations tested. This also occurred in medium supplemented with $4 \%$ and $8 \%$ of extract SMC. In line with this, having too high nutrients disrupts the explants ability to consume the right amount of nutrient. The extract form of SMC also produced higher impact on the growth of explant compared to powdered SMC due to the easier absorption of nutrient in extract form. Hence it can be concluded that the $2 \%$ extract is the most optimum concentration for a multiple shoot regeneration of $C$. nutans.

Both powdered and extracts SMC had emerged positive feedback on the production of shoots with varieties of length. There is similar finding as recoded for Hashim et al. (2017). However, the extracellular enzymes in the extracts exerted an effect by elongating the cell wall of the plants and provide a rapid secondary growth (Hayashi et al., 2005). Therefore, the extract SMC induced higher length of shoots compared to powdered SMC at the same concentrations. This shows that extract SMC is more effective compared to powdered form for multiple shoots induction of $C$. nutans. There is a slight increase in the length of the shoots from the $2 \%$ to $4 \%$ and a sharp increase in length for $8 \%$ powdered SMC. The slight increase could be due to both concentrations are not containing enough nutrients for the explants to support the growth of shoots as compared to the extract SMC.

The number of leaves may increase steadily using the extracts, but the same concentration of powdered SMC could not give the same effect towards the regeneration of leaves. This is probably because the extracts contain several beneficial extracellular enzymes which were extracted from the powdered SMC (Seon et al., 2013). The extracellular enzymes extracted were cellulase, betaglucanase, laccase lignin peroxide, amylase and xylanase. These enzymes might help to increase the propagation by increasing the cellulose biosynthesis in the explants (Hayashi et al., 2005). Hence, in this project, it has proved that SMC which is an agricultural waste, is able to be converted into useable product for enhancing the growth of plant.

\section{Conclusion}

It can be concluded that the addition of mercuric chloride in the surface sterilization method have enhanced the efficiency in producing sterile plantlets of C. nutans. Hence, it can be considered as the most suitable and stable protocol for the surface sterilization of $C$. nutans. The used of plant hormone which is BAP enable the production of higher number of shoots and leaves for micropropagation of $C$. nutans within 4 weeks. $1.0 \mu \mathrm{M}$ of BAP is the optimum concentration that gives better result in number of shoots emerged and $2.0 \mu \mathrm{M}$ BAP able to produce higher number of leaves. The treatment using media added with BAP and SMC shows better performance compared to media supplemented with BAP only. Both powdered and extract SMC had improved on the production of leaves and shoots for $C$. nutans in vitro. The extracts of SMC showed higher number of leaves, number of shoots and length of shoots compared to the powdered SMC and control. The findings showed that there is enhancement effect on the combination of BAP with extracts of SMC where more than $100 \%$ higher regeneration rate was achieved when compared with the BAP alone. Thus, this method has high potential for future research in producing mass propagation of $C$. nutan and other related studies by reducing the usage of plant growth regulator which can reduce the cost of production of agricultural tissue culture plants.

\section{Acknowledgement}

The authors would like to take this opportunity to thanks and appreciation to all the related people of both universities (Universiti Malaysia Pahang and Universiti Teknologi MARA, Perak Branch) for facility and financial support in this research.

\section{Author's Contributions}

Wan Nurul Hidayah: Analysed data and checking on the manuscript.

Tan Suat Hian: Analysed data and checking on the manuscript.

Siti Hamidah Radiyah Shiekh Mahmud: Performed the experiment and wrote the manuscript.

Engku Fatimah Syairah Engku Safruddin: Performed some of the experiment.

\section{Ethics}

This article is original and contains unpublished material. The corresponding author confirms that all of the other authors have read and approved the manuscript and no ethical issues involved. 


\section{References}

Akinyele, J.B., S. Fakoya and C.F. Adetuyi, 2012. Antigrowth factors associated with Pleurotus ostreatus in a submerged liquid fermentation. Malaysian J. Microbiol., 8: 135-140.

Bouhouce, N. and T. Ksiksi, 2007. An efficient in vitro plant regeneration system for the medicinal plant Teucrium stocksianum Boiss. Plant Biotechnol. Report, 1: 179-184. DOI: 10.1007/s11816-007-0033-4

Gulab, S.T., M. Pandey, R. Sharma, B.S. Sanodiya and G.B.K.S. Prasad et al., 2011. Factors affecting in vitro propagation of Momordica balsamina: A medicinal and nutritional climber. Physiol. Molecular Biol. Plant, 17: 193-197.

DOI: $10.1007 / \mathrm{s} 12298-011-0052-\mathrm{z}$

Hashim, S.N., W.N.H. Wan Anuar, C.C. Tay and S.H.R.S. Mahmud, 2017. Evaluation on the effects of $P$. ostreatus spent mushroom compost and BAP hormone towards $C$. nutans in vitro culture. J. Fundamental Applied Sci., 9: 920-936.

DOI: 10.4314 /jfas.v9i4S.55

Hayashi, T., K. Yoshida, Y.W. Park, T. Konishi and K.I. Baba, 2005. Cellulose metabolism in plants. Int. Rev. Cytol., 24: 1-34.

DOI: 10.1016/S0074-7696(05)47001-1

Janarthanam, B. and E. Sumathi, 2010. In vitro regeneration of Justicia gendarussa Burm f. Libyan. Int. J. Agric. Res. Center, 1: 284-287.

Seon, H.L., Y.H. Lee and H.W. Kang, 2013. Efficient recovery of lignocellulolytic enzymes of spent mushroom compost from oyster mushrooms, Pleurotus spp. and potential use in dye decolorization. J. Mycobiol., 41: 214-220. DOI: 10.5941/MYCO.2013.41.4.214

Singh, V., A. Tyagi, P.K. Chauhan, P. Kumari and S. Kaushal, 2011. Identification and prevention of bacterial contamination on explant used in plant tissue culture labs. Int. J. Pharmacy Pharm. Sci., 3: 160-168.

Soibam, P.D., S. Kumaria, S.R. Rao and P. Tandon, 2013. In vitro propagation and assessment of clonal fidelity of Nepenthes khasiana Hook. f.: A medicinal insectivorous plant of India. Acta Phys. Plant, 35: 2813-2820.

DOI: $10.1007 / \mathrm{s} 11738-013-1314-\mathrm{X}$

Srivastava, L.M., 2001. Plant growth and development: hormones and environment. Imprint Elsevier Sci. USA, 92: 846-846. DOI: 10.1093/aob/mcg209

Suriyavathana, M. and M. Kumar. 2010. In vitro shoot development in Blepharis Repnes. Int. J. Applied Biol. Pharma. Technol., 1: 1098-1100.

Tan, S.H. and M. Mahmood, 2013. Effect of precursors on flavonoid production in Pegaga cell suspension cultures. Proceedings of the Malaysian Technical Universities Conference Engineering Technology, Dec. 3-4, Kuantan, Pahang, pp: 1-2.
Tan, S.H., 2017. Morphological and biochemical characteristics on different accession of Pegaga. Indian J. Sci. Technol., 10: 0974-6846. DOI: $10.17485 / \mathrm{ijst} / 2017 / \mathrm{v} 10 \mathrm{i} 2 / 110370$

Tan, S.H., M. Mahmood and A. Arbakariya, 2013. Synergism Effect between inoculum size and aggregate size on flavonoid production in Centella asiatica (L.) urban (Pegaga) cell suspension culture. Int. J. Res. Eng. Technol., 2: 244-253.

Tan, S.H., R. Musa, A. Arbakariya and M. Mahmood, 2010. Effect of plant growth regulators on callus, cell suspension and cell line selection for flavonoid production from Pegaga (Centella asiatica L. urban). Am. J. Biochem. Biotechnol., 6: 284-299. DOI: 10.3844/ajbbsp.2010.284.299

Taški-Ajduković, K.J. and D.M. Vasić, 2005. Different sterilization methods for overcoming internal bacterial infection in sunflower seeds. Zbornik Matice Srpske za Prirodne Nauke, 109: 59-64. DOI: 10.2298/ZMSPN0519059T

Thomas, T.D. and S. Shankar, 2009. Multiple shoot induction and callus regeneration in Sarcostemma brevistigma Wight and Arnott, a rare medicinal plant. Plant Biotechnol. Reports, 3: 67-74. DOI: 10.1007/s11816-008-0076-1

Tiew, W.P., P.X. Wen, C.J. Han and G.A. Akowuah, 2014. Effect of methanol extract of Clinacanthus nutans on serum biochemical parameters in rats. J. Applied Phar., 6: 77-86.

Yong, Y.K., J.J. Tan, S.S. Teh, S.H. Mah and G.C. Ee et al., 2013. Clinacanthus nutans extracts are antioxidant with antiproliferative effect on cultured human cancer cell Lines. Evidence-Based Complementary Alternative Med.

DOI: $10.1155 / 2013 / 462751$

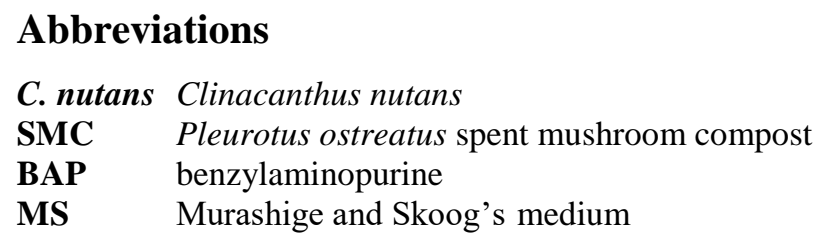

\section{Abbreviations}

nutans

MS Murashige and Skoog's medium 